\title{
From Self-inclusion and Host-guest Complexes to Channel Structures
}

\author{
Mario Cetina ${ }^{\mathrm{a}, *}$ and Kari Rissanen \\ NanoScience Center, Department of Chemistry, University of Jyväskylä, P.O. Box 35, 40014 Jyväskylä, Finland \\ ${ }^{a}$ Permanent address: Department of Applied Chemistry, Faculty of Textile Technology, \\ University of Zagreb, Prilaz baruna Filipovića 28a, HR-10000 Zagreb, Croatia
}

RECEIVED JANUARY 31, 2012; REVISED JULY 19, 2012; ACCEPTED SEPTEMBER 21, 2012

\begin{abstract}
Various supramolecular interactions are applied as driving forces in self-assembly and molecular recognition processes. Single crystal X-ray diffraction method is especially important for solid-state studies of non-covalent interactions as it reveals their influence on the molecular and supramolecular structures. This paper discusses structures of two completely different types of compounds in which a variety of intermolecular interactions are involved. It will be shown that strong and weak intermolecular hydrogen bonds in $N$-alkylammonium resorcinarene salts, depending on the type of anion, inclusion of resorcinarene upper rim pendant group or solvent molecules into the cavity, strongly affect overall conformation of the resorcinarene core. On the other hand, very weak hydrophobic interactions in palladium(II) pincer complexes form channel structures. (doi: 10.5562/cca2058)
\end{abstract}

Keywords: X-ray structure, supramolecular chemistry, hydrogen bonding, hydrophobic interaction, resorcinarene, palladium complex

\section{INTRODUCTION}

The rational design and synthesis of novel solid-state architectures are of current interest in the field of supramolecular chemistry and crystal engineering due to intriguing structural motifs that can be created by various intermolecular interactions. Supramolecular chemistry applies molecular recognition processes which rest heavily on understanding of the recognition properties of the functional groups involved in these interactions, i.e. on molecular information stored in the interacting species. ${ }^{1}$ It aims at constructing highly complex, functional chemical systems from components held together by intermolecular interactions. Various supramolecular interactions are used as tools in supramolecular chemistry and especially in crystal engineering in an order to develop novel functional materials. Besides conventional strong hydrogen bonds $(\mathrm{O}-\mathrm{H} \cdots \mathrm{O}, \mathrm{N}-\mathrm{H} \cdots \mathrm{O}$ etc. $)$ that play a dominant role in supramolecular assembling, the successful building of supramolecular architectures can be accomplished also by much weaker and more subtle intermolecular interactions, such as $\mathrm{C}-\mathrm{H} \cdots \mathrm{O}$ and $\mathrm{C}-\mathrm{H} \cdots \mathrm{N}$ hydrogen bonds, $\mathrm{C}-\mathrm{H} \cdots \pi$ and $\pi \cdots \pi$ interactions and halogen bonds. ${ }^{2}$ Understanding of the nature of supramolecular interactions and how to control them systematically is important in order to design new materials with desirable physical and chemical properties.
In this paper we discuss crystal structures of two completely different types of compounds in which great variety of intra- and intermolecular interactions are involved in the formation of their molecular and supramolecular structures. Being either very weak or strong the interactions can lead to extraordinary interesting structures with variety of applications and have crucial role in the formation of the final structure. Thus, in $N$-alkylammonium resorcinarene salts, having halides (chlorides and bromides) as counteranions, strong intra- and intermolecular hydrogen bonds prevail and strongly affect conformation of the resorcinarene core. On the other hand, palladium(II) pincer complexes prefer to interact with themselves via hydrophobic interactions. Although very weak, these interactions can overrule stronger ones which could be also formed (e.g. $\mathrm{C}-\mathrm{H} \cdots \mathrm{O}$ hydrogen bond), leading to channel structures.

\section{STRONG INTRA- AND INTERMOLECULAR HYDROGEN BONDS IN $N$-ALKYLAMMONIUM RESORCINARENE SALTS}

Due to their easy availability and versatile nature, resorcinarenes have been widely used as host molecules and models for receptors as well as building blocks in crystal engineering and self-assembly studies in

\footnotetext{
* Author to whom correspondence should be addressed. (E-mail: mario.cetina@ttf.hr)
} 

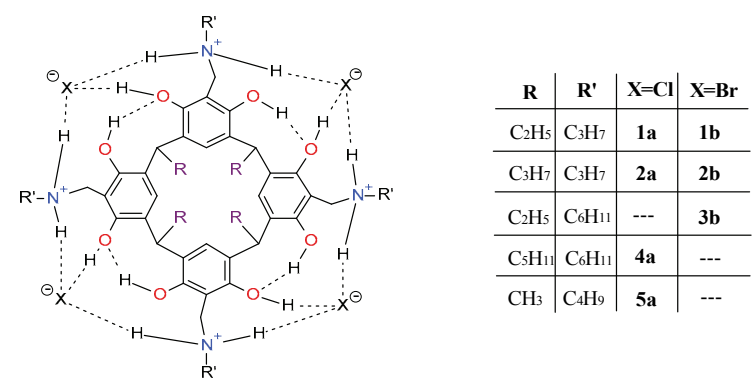

Scheme 1. The $N$-alkylammonium resorcinarene cavitands, chlorides and bromides. ${ }^{8 \mathrm{a}, 9 \mathrm{a}}$

supramolecular chemistry. As an object of such studies, they can form self-inclusion complexes or they can bind neutral molecules or ionic species, so forming solvates and other complexes with molecules or ions present in the crystallization solution. The possibility of trapping small guest molecules is a consequence of the fact that resorcinarene is a concave bowl-shape molecule made up by intramolecular $\mathrm{O}-\mathrm{H} \cdots \mathrm{O}$ hydrogen bonds. Hydrophilic upper rim of the molecule via hydroxyl groups can form intermolecular hydrogen bonds, while hydrophobic lower rim of the molecule, an electron-rich cavity, can form complexes through $\mathrm{C}-\mathrm{H} \cdots \pi, \pi \cdots \pi$ and cation $\cdots \pi$ interactions. Multiple hydrogen-bond interactions are used for the design of self-assembled structures capable of molecular encapsulation. ${ }^{3}$ Thus, intermolecular hydrogen bonds are responsible for the building of several complicated self-assembled structures involving resorcinarenes, such as 1:1 inclusion complexes, ${ }^{4}$ dimeric, ${ }^{5}$ hexameric ${ }^{6}$ and tubular ${ }^{7}$ assemblies.

The charge-neutral $\mathrm{N}$-alkylammonium resorcinarene halides, with strong circular hydrogen bond seam between the ammonium moieties and halide anions, can form cavitand-like structures. ${ }^{8,9 a}$ Halides as free ions are good proton acceptors, assisted by their intrinsic charge, and have been seen in many synthetic receptor systems and within solid-state architectures. The $\mathrm{N}$ alkylammonium resorcinarene halides, ${ }^{8 a, 9 a}$ chlorides (1a, $\mathbf{2 a}, \mathbf{4 a}$ and $\mathbf{5 a})$ and bromides $(\mathbf{1} \mathbf{b}-\mathbf{3 b})$ are presented in Scheme 1.

As expected, because of steric reasons, all $\mathrm{N}$ alkylammonium resorcinarene cavitands with cyclohexyl ring at the upper rim of the resorcinarene core (R', Scheme 1) crystallized as host-guest complexes. The other resorcinarene salts, with the exception of 1a and 5a, are self-included dimers. The dimers of these resorcinarene halides consist of two self-included resorcinarene tetracations and six halides, bromides or chlorides, and is formed via $\mathrm{N}-\mathrm{H} \cdots \mathrm{X}$ hydrogen bond ( $\mathrm{X}$ $=\mathrm{Br}, \mathrm{Cl}$ ) between ammonium nitrogen atoms and halides. Because of hydrogen-bonded array of ammonium and halide ions the shallow cavity of the resorcinarene is extended. The first example of self-included dimer

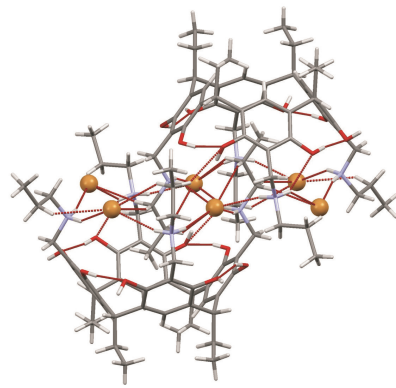

(a)

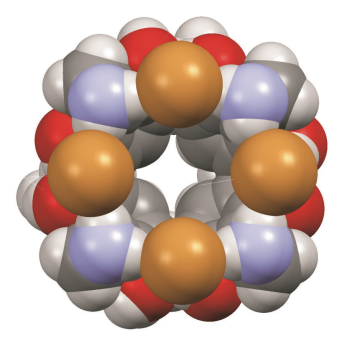

(b)
Figure 1. (a) Cappped stick representation of $\mathbf{1 b}$ dimer; (b) CPK plot of $\mathbf{1 b}$ (from the top), showing an almost perfect square formed by four ammonium nitrogen atoms and four bromides (the upper rim propyl chains have been omitted for clarity). ${ }^{9 \mathrm{a}}$

formed via $\mathrm{N}-\mathrm{H} \cdots \mathrm{Br}$ hydrogen bonds is compound $\mathbf{1 b}$, with the propyl group at the upper and ethyl at the lower rim of the resorcinarene core (Figure 1). The $\mathrm{N}-\mathrm{H} \cdots \mathrm{Br}$ hydrogen bonds are supported in dimer formation by two $\mathrm{C}-\mathrm{H} \cdots \pi$ interactions as terminal $\mathrm{C}-\mathrm{C}$ bond of the propyl group is directed towards electron rich cavity.

The conformation of the lower rim of the resorcinarene core can be defined by distances between phenyl rings centroids $(C g \cdots C g)$, while the upper rim can be defined by distances between opposite nitrogen atoms $(\mathrm{N} \cdots \mathrm{N})$ and halides $(\mathrm{X} \cdots \mathrm{X})$, Table 1 . The nitrogen atoms in $\mathbf{1 b}$ form an almost perfect square, with the distance difference of $0.16 \AA$, while the distance difference between bromides is $0.34 \AA$. As the distance difference between the opposite phenyl ring centroids is

Table 1. Distance differences $(\AA)$ between ring centroids $(C g \cdots C g)$, nitrogen atoms $(\mathrm{N} \cdots \mathrm{N})$ and halides $(\mathrm{X} \cdots \mathrm{X})$ defining conformation of the resorcinarene core ${ }^{\mathrm{a}}$

\begin{tabular}{llll}
\hline Structure & $C g \cdots C g$ & $\mathrm{~N} \cdots \mathrm{N}$ & $\mathrm{X} \cdots \mathrm{X}$ \\
\hline $\mathbf{1} \mathbf{a}^{9 \mathrm{a}}$ & 0.66 & 0.59 & 0.81 \\
$\mathbf{1 b}^{9 \mathrm{a}}$ & 0.59 & 0.97 & 0.53 \\
$\mathbf{2 a} \cdot \mathrm{H}_{2} \mathrm{O}^{9 \mathrm{a}}$ & 0.05 & 0.16 & 0.34 \\
$\mathbf{2 a} \cdot \mathrm{BuOH} \cdot 0.5 \mathrm{H}_{2} \mathrm{O}^{9 \mathrm{a}}$ & 0.01 & 0.05 & 0.40 \\
$\mathbf{2} \mathbf{b}^{9 \mathrm{a}}$ & 0.02 & 0.48 & 0.26 \\
$\mathbf{3}^{9 \mathrm{a}}$ & 0.80 & 2.14 & 0.55 \\
$\mathbf{4 a}^{9 \mathrm{a}}$ & 0.19 & 0.25 & 0.30 \\
$\mathbf{5 a}^{8 \mathrm{a}}$ & 0.03 & 0.03 & $0.71^{\mathrm{b}}$ \\
\hline
\end{tabular}

${ }^{a}$ The reference for each structure is given alongside the number.

${ }^{\mathrm{b}}$ Only one value is given for two independent molecules of $\mathbf{5 a}$ as three chlorides in one independent molecule are disordered. 


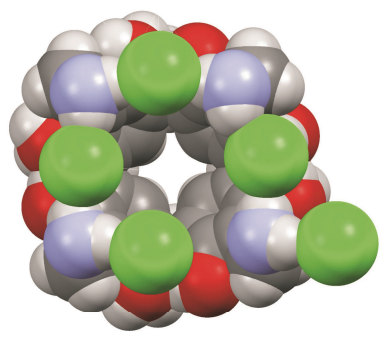

(a)

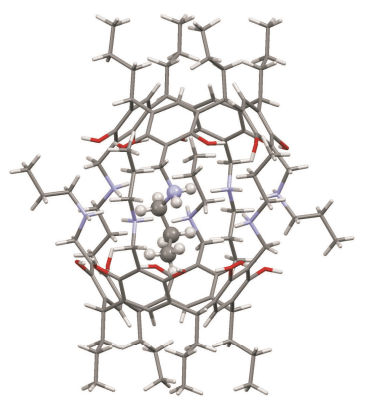

(b)

Figure 2. (a) $\mathrm{CPK}$ plot of $\mathbf{2 a} \cdot \mathrm{BuOH} \cdot 0.5 \mathrm{H}_{2} \mathrm{O}$ (from the top), showing slightly distorted conformation of the resorcinarene core (the upper rim propyl chains have been omitted for clarity); (b) Capped stick representation of $2 \mathbf{a} \cdot \mathrm{BuOH} \cdot 0.5 \mathrm{H}_{2} \mathrm{O}$ dimer, showing twisted self-included propyl chain in ball and stick style (chlorides have been omitted for clarity). ${ }^{9 a}$

also almost equal, the resorcinarene core in this structure is nearly symmetrical. Such conformation with similar values of distance differences is also observed in self-included dimer of $\mathbf{2 b}$.

It is interesting to note that resorcinarene core conformation slightly differ in two structures of chloride analogue of $\mathbf{2 b}$, viz. 2a. Compound 2a crystallizes in two slightly different forms, a monohydrate and $n$-butanol solvate hemihydrate. The chloride anions and ammonium cations in $\mathbf{2 a} \cdot \mathrm{H}_{2} \mathrm{O}$ form again an almost perfect square. On the other hand, the resorcinarene core in $2 \mathrm{a} \cdot \mathrm{BuOH} \cdot 0.5 \mathrm{H}_{2} \mathrm{O}$ adopts slightly distorted conformation. The distance difference between nitrogen atoms is $0.48 \AA$, slightly bigger than that in $\mathbf{1 b}$ and $\mathbf{2 b}$. In this structure, one hydrogen atom of ammonium nitrogen is not involved in the formation of $\mathrm{N}-\mathrm{H} \cdots \mathrm{Cl}$ hydrogen bonds inside resorcinarene core and it points to the chloride which is outside of the dimer (Figure 2a). This is accompanied with completely different conformation of the self-included propyl group which is twisted (Figure $2 \mathrm{~b}$ ). Such orientation of the propyl group prevents $\mathrm{C}-\mathrm{H} \cdots \pi$ interaction formation and this dimer is built only by $\mathrm{N}-\mathrm{H} \cdots \mathrm{Cl}$ hydrogen bonds.

In two $\mathrm{N}$-alkylammonium resorcinarenes with propyl (1a) and butyl (5a) chain at the upper rim of the resorcinarene core crystallization conditions resulted in an unexpected disruption of the self-included dimer, and instead inclusion of solvent molecules into the cavity was observed. Thus, both compounds crystallize as host-guest complexes with two independent cations and eight chlorides in the asymmetric unit. Inclusion of acetonitrile molecules in resorcinarene 5a and dichloromethane molecules in $\mathbf{1 a}$ resulted in distorted conformation of the resorcinarene core. In the case of 1a, even lower rim is distorted as distance differences between ring centroids are 0.66 and $0.59 \AA$ (Figure $3 \mathrm{a}$ ).

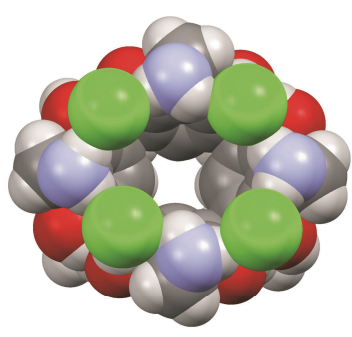

(a)

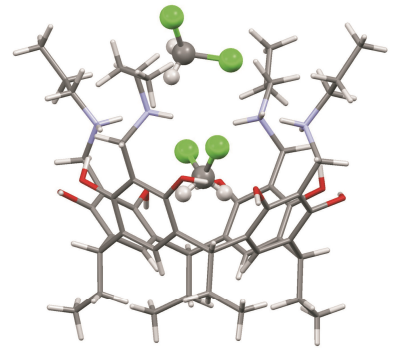

(b)
Figure 3. (a) CPK plot of one independent cation of 1a, showing distorted conformation of the upper rim cation-anion belt (upper rim propyl chains have been omitted for clarity); (b) Capped stick representation of one independent cation and included dichloromethane molecules in 1a, showing orientation of the dichloromethane molecules into the cavity (the chloride anions have been omitted for clarity and included dichloromethane molecules are presented in ball and stick style). ${ }^{9 \mathrm{a}}$

From these data is obvious that the geometry of the resorcinarene core could be markedly influenced by the inclusion of solvent molecules. In 1a, this is a result of repulsion between dichloromethane chlorines and atoms of resorcinarene skeleton. Dichloromethane molecules fill up the cavities of both independent resorcinarene cations with the host:guest ratio of 1:2 (Figure 3b). The chlorine atoms of the dichloromethane molecules within the same cavity are rotated and displaced in staggered orientation in order to minimise their mutual repulsion.

In the cavity of both independent cations of $\mathbf{5 a}$ two acetonitrile molecules are included (Figure 4a). The acetonitrile molecule at lower position (Figure $4 \mathrm{~b}$ ) is close to one ammonium nitrogen atom to which it forms $\mathrm{N}-\mathrm{H} \cdots \mathrm{N}$ hydrogen bond. Its position is additionally fixed by one $\mathrm{C}-\mathrm{H} \cdots \mathrm{Cl}$ hydrogen-bond and by one

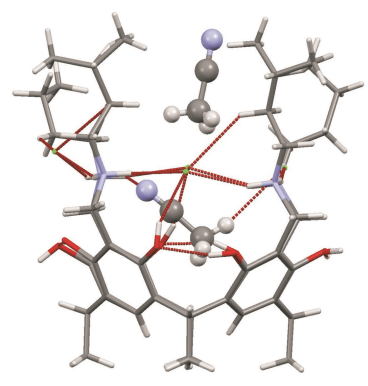

(a)

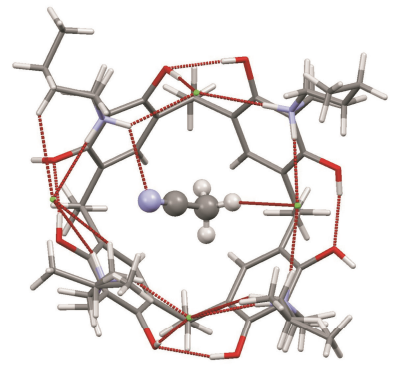

(b)
Figure 4. Capped-stick representation of one independent cation of 5a, showing position of included acetonitrile molecules in the cavity: (a) both molecules (side view); (b) molecule at lower position (from the top). The included solvent molecules are presented in ball and stick style. ${ }^{8 \mathrm{a}}$ 


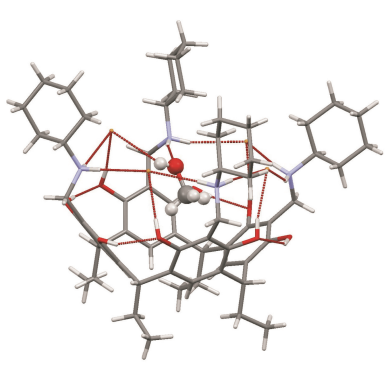

(a)

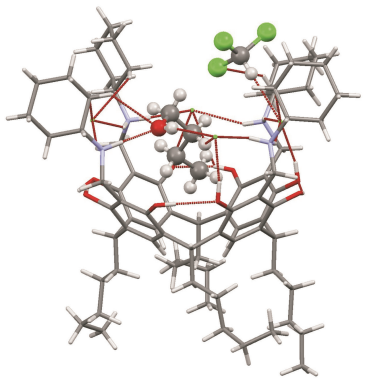

(b)
Figure 5. Capped-stick representation of: a) $\mathbf{3 b}$ and b) $\mathbf{4 a}$, showing position of the included solvent molecules in the cavity (bromides in $\mathbf{3 b}$ and chlorides in $\mathbf{4 a}$ have been omitted for clarity and included methanol molecule in $\mathbf{3 b}$ and $n$-butanol and chloroform molecules in $\mathbf{4 a}$ are presented in ball and stick style). ${ }^{9 \mathrm{a}}$

$\mathrm{C}-\mathrm{H} \cdots \pi$ interaction formed between guest molecule and electron rich cavity of resorcinarene. The second acetonitrile molecule sits on the top of cavity in the perpendicular position. Such orientation minimizes repulsion between atoms of the acetonitrile molecule and those of upper rim butyl chain of the host molecule.

When the cyclohexyl ring is at the upper rim of the resorcinarene core, the self-inclusion and subsequent dimer formation is not possible due to the sterically very bulky cyclohexyl groups. In the case when ethyl group is at the lower rim of the resorcinarene core (3b) resorcinarene shows selectivity towards methanol (Figure 5a) and in the case of pentyl group (4a) towards $n$-butanol (Figure 5b). In addition to the deeply included $n$-butanol in 4a, one molecule of chloroform sits also on top of the cation-anion belt. Hydroxyl group of the $n$-butanol in $\mathbf{4 a}$ is situated on the cation-anion belt, while for the included methanol molecule in $\mathbf{3 b}$ it is situated slightly below the plane of the cation-anion belt. However, in both structures, it is in a position which enables $\mathrm{O}-\mathrm{H} \cdots \mathrm{Br}$ and $\mathrm{O}-\mathrm{H} \cdots \mathrm{Cl}$ hydrogen bond formation in $\mathbf{3 b}$ and $\mathbf{4 a}$, respectively. The cation-anion belt in $\mathbf{3 b}$ is more distorted than in any other previously described structure, so that resorcinarene core adopts highly distorted conformation. This is a consequence of the larger sterical demand of the cyclohexyl groups and the bromide anions. On the other hand, resorcinarene core in $\mathbf{4 a}$ adopts slightly distorted conformation, probably caused by inclusion of $n$-butanol and chloroform molecules.

The $n$-butanol molecule in $\mathbf{4 a}$ is linked to the cation also by $\mathrm{C}-\mathrm{H} \cdots \pi$ interaction formed between hydrogen of the terminal carbon atom of $n$-butanol molecule and phenyl ring of resorcinarene, while the chloroform molecule is linked to one of the chlorides by $\mathrm{C}-\mathrm{H} \cdots \mathrm{Cl}$ hydrogen bond. It should be also added that $\mathrm{N}$-alkylammonium resorcinarene salts with large non-spherical anions (pic- rate, nitrate and triflate) also form self-included and host-guest complexes. ${ }^{9 b}$ In these structures, the conformation of the resorcinarene core is also highly influenced by inclusion of solvent molecules, upper rim pendant group or type of anion.

\section{VERY WEAK HYDROPHOBIC INTERACTIONS IN PALLADIUM PINCER COMPLEXES}

The studies of the relationship between the molecular structure and very weak non-covalent interactions have been usually taken with the aim to control self-assembly process of molecular building blocks and above all in a wish to give well defined supramolecular architectures in the solid-state. Thus, the synthesis and characterization of molecular-based cages and capsules, ${ }^{10}$ spheres ${ }^{11}$ and tubes ${ }^{7,12}$ have attracted significant research efforts recently for the development of novel materials and compounds with molecular recognition ability. Considerable interest has attracted structures and properties of porous organic and metal-organic crystalline materials which can form pores or channels in the crystalline state, because of their unique potential capabilities in gas storage, ion exchange and catalysis. ${ }^{3 c, 13}$ Pincer complexes are well known compounds as precursors to further functionalized complexes for applications in e.g. catalysis, bond activation, sensors and switches. ${ }^{14}$

In the last decade, a lot of attention is devoted to $\{2,6$-bis[(di-t-butylphosphino)methyl]phenyl $\}$ palladium (II) (PCPPd) pincer complexes, and all structures of this type of compounds have been published in this period (since 2002). ${ }^{15}$ These interesting complexes can form different types of assemblies by various intermolecular interactions. Johansson et al. $^{15 \mathrm{a}}$ have published structures of metal-organic crystals of PCPPdOH (1) hydrate, $\mathrm{PCPPdONO}_{2}$ (2) and $\mathrm{PCPPdNO}_{2}$ (3) pentane solvate (Scheme 2). Their topologies of supramolecular structures give rise to a range of different molecular architectures, from strongly solvent-bridged hydrogen-bonded dimers of 1, over weakly hydrogen-bonded zigzag chains in $\mathbf{2}$ to $3 \mathrm{D}$ quartz net in $\mathbf{3}$.

The most interesting structure in this series is the last one, pentane solvate of $\mathrm{PCPPdNO}_{2}$ (3), which forms a porous framework with potential free volume of $17 \%$. ${ }^{15 a}$
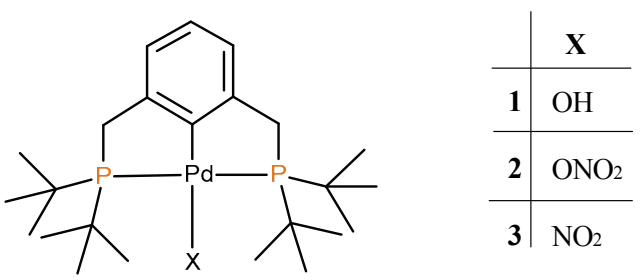

Scheme 2. Chemical structures of palladium(II) pincer complexes. $^{15 \mathrm{a}}$ 


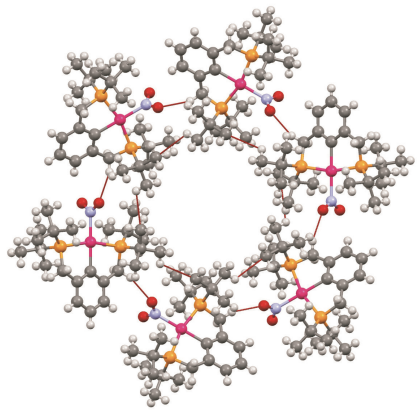

(a)

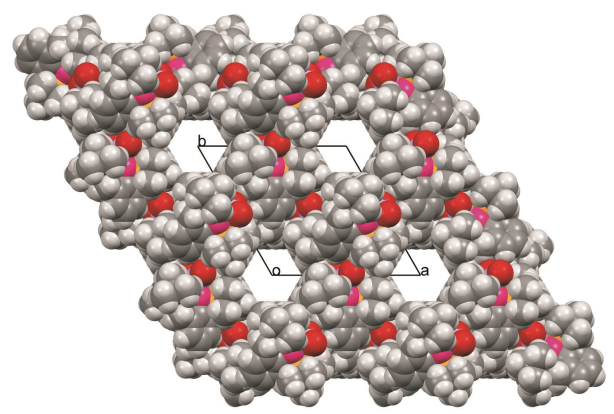

(b)

Figure 6. Channel(s) in pentane solvate of $\mathrm{PCPPdNO}_{2}$ (3): a) ball and stick representation; (b) CPK plot viewed down the $c$ axis. ${ }^{15 a}$

The supramolecular structure is based on two different types of interactions, but connecting the same neighbouring molecules. The first one is weak hydrogenbonded interaction which involves oxygen atom of the $\mathrm{NO}_{2}$ group as protonacceptor and hydrogen atom of methylene group as donor. In addition, the tert-butyl groups in $\mathbf{3}$ prefer to interact with itself via hydrophobic interactions and therefore facilitate the formation of hydrophobic channels (Figure 6).

Each molecule of the complex is linked through these contacts to four neighbouring molecules, thus making a four-connected three-dimensional net and

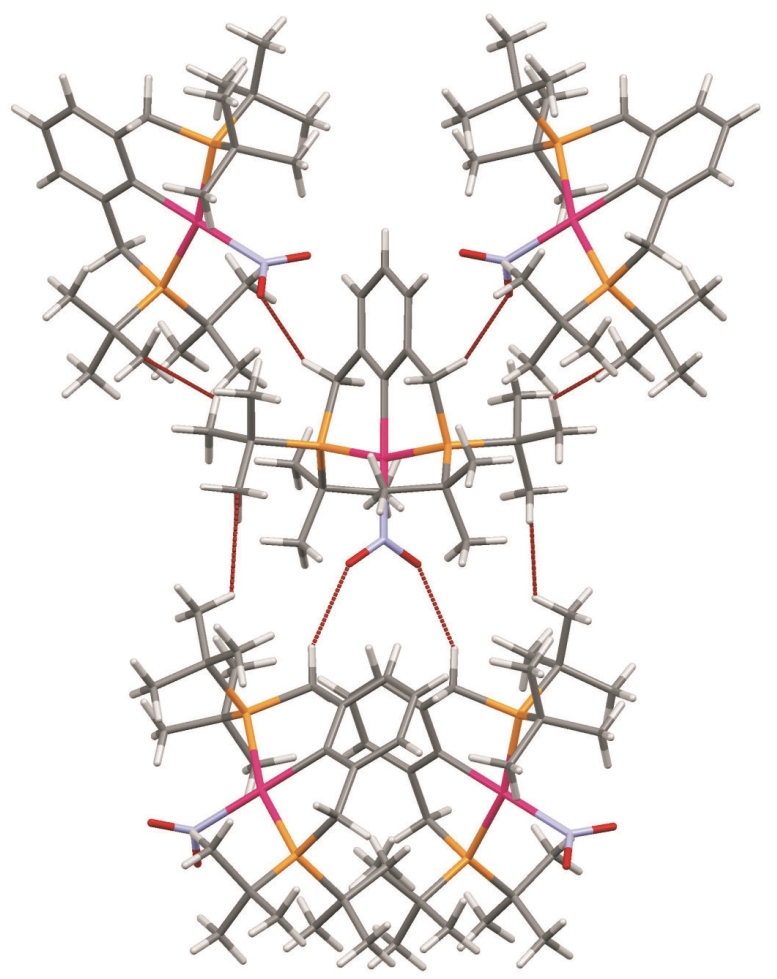

Figure 7. Part of the crystal structure of $\mathbf{3}$ showing $\mathrm{H}_{2} \mathrm{CH} \cdots \mathrm{CH}_{3}$ and $\mathrm{C}-\mathrm{H} \cdots \mathrm{O}$ contacts between neighbouring molecules. $^{15 \mathrm{a}}$ each molecule participates in the formation of two channels (Figure 7). The $c$-axis constitutes the hexagonal channel of the structure as is shown in Figure 6b. The inner walls of the channel are built up by tert-butyl groups (Figure 6) and they form a completely hydrophobic environment. The interior of the channel contains a very badly resolved residual electron density indicating the presence of highly disordered residual solvent, as is stated in the paper, ${ }^{15 a}$ the most probably pentane. Thus, large amounts of solvent molecules are incorporated into an apparently porous network of this structure.

The pentane solvate of $\mathrm{PCPPdNO}_{2}$ (3) crystallizes in enantiomorphic hexagonal space groups $P 6_{1} 22$ (CSD Refcode: NIQYOC). Heating of these crystals at $120{ }^{\circ} \mathrm{C}$ in high vacuum the structure was retained. However, $\mathrm{X}$-ray single crystal study revealed that the same compound crystallizes now in space group $P 6_{5} 22$ (CSD Refcode: CIQZAE), but with less amount of disordered solvent in the channel. Thus, supramolecular organiza-

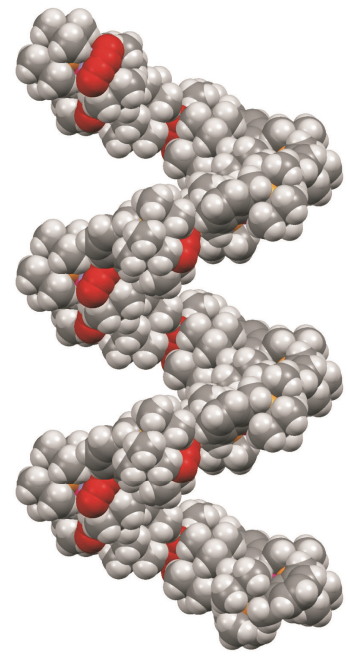

(a)

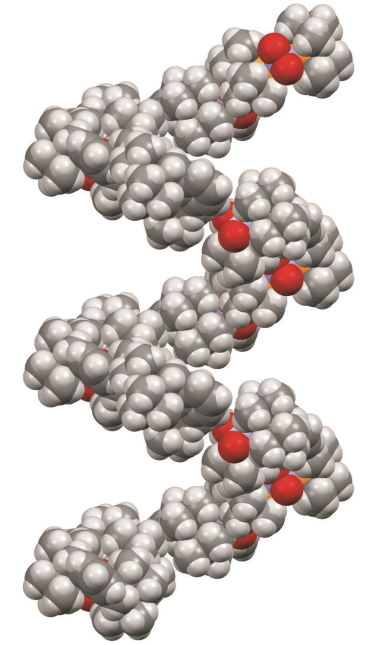

(b)
Figure 8. CPK plot of: a) right-handed helix and b) lefthanded helix of $\mathbf{3}^{15 a}$ 
tion in both structures results in the formation of helix along the six-fold axis of symmetry, but the handedness of the helix is different. Right-hand complexes crystallize in $P 6_{1} 22$ space group and left-handed in $P 6_{5} 22$ (Figure 8). Two such helices are mutually interweaved and tightly packed in both structures.

In view of the interesting properties of $\mathbf{3}$ and its promising potential in porous materials we have investigated possibilities of channel formation with similar pincer complexes containing terminal metal halides, chloride and bromide, and this paper is in preparation and will be published elsewhere. ${ }^{16}$ This research showed that channel formation is the result of very weak hydrophobic interactions and possible solvate template effect, and not of weak hydrogen bonds (e.g. $\mathrm{C}-\mathrm{H} \cdots \mathrm{O}$ in 3 ). Based on these preliminary results the template effect of the solvent molecules cannot be completely ruled out as a driving force or may work in a synergy with other interactions responsible for channel formation as described in the paper by Johansson et al. ${ }^{15 a}$

\section{CONCLUSIONS}

In this paper is presented how various intermolecular interactions influence on molecular and supramolecular structures of two different types of compounds. In pentane solvate of palladium pincer complex $\mathrm{PCPPdNO}_{2}$ (3) tert-butyl groups prefer to interact with itself via very weak hydrophobic interactions, so facilitating the formation of channels in the presence of lipophilic molecules. In such a way, this compound makes channels with a completely hydrophobic environment and disordered solvent in it, as well as right- and left-handed helices depending on the space group in which compound crystallizes. Together with this interaction solvate template effects could be also responsible for channel formation, so governing the crystal packing and forming very interesting and extraordinary structure for such type of compounds. From all known structures of $\{2,6$-bis [(di-t-butylphosphino)methyl]phenyl $\}$ palladium (II) complexes $\mathrm{PCPPdNO}_{2}$ (3) is the only one which forms channels.

In the case of $N$-alkylammonium resorcinarene cavitand-like structures, depending on the nature and length of the upper rim chain and size of the solvent or guest molecule(s) used for recrystalization studies, two different types of complexes are formed, self-included dimers or host-guest complexes. In these structures, strong hydrogen bonds between cations, anions and guest molecules prevail and strongly affect the conformation of the resorcinarene core, from nearly symmetrical in $\mathbf{1 b}, \mathbf{2} \mathbf{a} \cdot \mathrm{H}_{2} \mathrm{O}$ and $\mathbf{2} \mathbf{b}$ to highly distorted in $\mathbf{3 b}$. Thus, both the nature of the anion and the included solvent molecules has an impact to the solid state conformation of the resorcinarene core. It is also interesting that inclusion of the guest molecule is not crucial factor for distortion of the resorcinarene core (e.g. in the case of $n$-butanol molecule in $\mathbf{4 a}$ ). These structures manifest the difficulty of structure control and prediction due to competing of multiple interactions in the crystalline state.

Acknowledgements. Authors would like to thank to all collaborators who participate in two projects mentioned in this paper. KR kindly thanks the Academy of Finland for financial support (grants 130629, 122350, 140718). MC is grateful to all colleagues at the Department of Chemistry, University of Jyväskylä, Finland, for kindness and help.

\section{REFERENCES}

1. (a) J.-M. Lehn, Supramolecular Chemistry: Concepts and Perspectives, Wiley-VCH, Weinheim, 1995; (b) J. W. Steed and J. L. Atwood, Supramolecular Chemistry, $2^{\text {nd }}$ Edition, John Wiley \& Sons, Ltd., 2009.

2. (a) T. Steiner, Angew. Chem. Int. Ed. 41 (2002) 48-76; (b) G. R. Desiraju, Acc. Chem. Res. 35 (2002) 565-573; (c) G. R. Desiraju, Angew. Chem. Int. Ed. 50 (2011) 52-59; (d) G. R. Desiraju, Cryst. Growth Des. 11 (2011) 896-898; (e) G. R. Desiraju and T. Steiner, The Weak Hydrogen Bond in Structural Chemistry and Biology, Oxford University Press, Oxford, 1999; (f) T. Steiner, J. Chem. Soc. Perkin. Trans. 21995 1315-1319; (g) T. Steiner and W. Saenger, Chem. Soc., Chem. Commun. (1995) 2087-2088; (h) M. Nishio, CrystEngComm 6 (2004) 130-158; (i) T. Steiner, E. B. Starikov, A. M. Amado, and J. J. C. Teixeira-Dias, J. Chem. Soc. Perkin. Trans. 21995 1321-1326; (j) C. A. Hunter and J. K. M. Sanders, J. Am. Chem. Soc. 112 (1990) 5525-5534; (k) C. G. Claessens and J. F. Stoddart, J. Phys. Org. Chem. 10 (1997), 254-272; (1) E. A. Meyer, R. K. Castellano, and F. Diederich, Angew. Chem. Int. Ed. 42 (2003) 1210-1250; (m) P. Metrangolo and G. Resnati, Science 321 (2008) 918-919; (n) K. Rissanen, CrystEngComm. 10 (2008) 1107-1113; (o) P. Metrangolo, T. Pilati, and G. Resnati, CrystEngComm 8 (2006) 946-947; (p) M. T. Johnson, Z. Džolić, M. Cetina, O. F. Wendt, L. Öhrström, and K. Rissanen, Cryst. Growth Des. 12 (2012) 362-368.

3. (a) J. L. Atwood, G. A. Koutsantonis, and C. L. Raston, Nature 368 (1994) 229-231; (b) G. W. Orr, L. J. Barbour, and J. L. Atwood, Science 285 (1999) 1049-1052; (c) J. L. Atwood, L. J. Barbour, and A. Jerga, Science 296 (2002) 2367-2369.

4. (a) D. Rudkevich and J. Rebek, Jr., Eur. J. Org. Chem. (1999) 1991-2005; (b) J. L. Atwood and A. Szumna, J. Supramol. Chem. 2 (2002) 479-482; (c) M. Nissinen, E. Wegelius, D. Falabu, and K. Rissanen, CrystEngComm. 28 (2000) 1-3.

5. (a) K. Murayama and K. Aoki, Chem. Commun. (1997) 119-120; (b) A. Shivanyuk, K. Rissanen, and E. Kolehmainen, Chem. Commun. (2000) 1107-1108; (c) H. Mansikkamäki, M. Nissinen, and K. Rissanen, Chem. Commun. (2002) 1902-1903; (d) H. Mansikkamäki, M. Nissinen, C. A. Schalley, and K. Rissanen, New. J. Chem. 27 (2003) 88-97; (e) H. Mansikkamäki, M. Nissinen, and K. Rissanen, CrystEngComm. 7 (2005) 519-526; (f) N. K. Beyeh, A. Valkonen, and K. Rissanen, Supramol. Chem. 21 (2009) 142-148.

6. (a) L. R. MacGillivray and J. L. Atwood, Nature 389 (1997) 469-472; (b) T. Gerkensmeier, W. Iwanek, C. Agena, R. Frölich, S. Kotila, C. Naher, and J. Mattay, Eur. J. Org. Chem. 9 (1999) 2257-2262; (c) K. Rissanen, Angew. Chem., Int. Ed. Eng. 44 (2005) 3652-3654; (d) N. K. Beyeh, M. Kogej, A. Åhman, K. 
Rissanen, and C. A. Schalley, Angew. Chem. Int. Ed. 45 (2006) 5214-5218.

7. (a) H. Mansikkamäki, M. Nissinen, and K. Rissanen, Angew. Chem. Int. Ed. Eng. 43 (2004) 1243-1246; (b) $\mathrm{H}$ Mansikkamäki, S. Busi, M. Nissinen, A. Åhman, and K. Rissanen, Chem. Eur. J. 12 (2006) 4289-4296.

8. (a) A. Shivanyuk, T. P. Spaniol, K. Rissanen, E. Kolehmainen, and V. Böhmer, Angew. Chem. Int. Ed. 39 (2000) 3497-3500; (b) M. Luostarinen, M. Nissinen, M. Nieger, A. Shivanyuk, and K. Rissanen, Tetrahedron (2007) 1254-1263.

9. (a) N. K. Beyeh, M. Cetina, M. Löfman, M. Luostarinen, A. Shivanyuk, and K. Rissanen, Supramol. Chem. 22 (2010) 737-750; (b) N. K. Beyeh, M. Cetina, and K. Rissanen, Cryst. Growth. Des. (2012) 4919-4926.

10. (a) P. Mal, B. Breiner, K. Rissanen, and J. R. Nitschke, Science 324 (2009) 1697-1699; (b) M. Yoshizawa, J. K. Klosterman, and M. Fujita, Angew. Chem. Int. Ed. 48 (2009) 3418-3438; (c) P. Mal, D. Schultz, K. Beyeh, K. Rissanen, and J. R. Nitschke, Angew. Chem. Int. Ed. 47 (2008) 8297-8301; (d) M. Fujita, M. Tominaga, A. Hori, and B. Therrien, Acc. Chem. Res. 38 (2005) 369-378; (e) S. Leininger, B. Olenyuk, and P. J. Stang, Chem. Rev. 100 (2000) 853-907; (f) D. L. Caulder and K. N. Raymond, Acc. Chem. Res. 32 (1999) 975-982; (g) D. J. Cram and J. M. Cram, Container Molecules and their Guests, Royal Society of Chemistry, Cambridge, 1994.

11. (a) H. Masu, K. Katagiri, T. Kato, H. Kagechika, M. Tominaga, and I. Azumaya, J. Org. Chem. 73 (2008) 5143-5146; (b) K. Suzuki, M. Kawano, S. Sato, and M. Fujita, J. Am. Chem. Soc. 129 (2007) 10652-10653; (c) L. T. Scott, M. M. Boorum, B. J. McMahon, S. Hagen, J. Mack, J. Blank, H. Wegner, and A. de Meijere, Science 295 (2002) 1500-1503.

12. (a) W. Liao, Y. Li, X. Wang, Y. Bi, Z. Su, and H. Zhang, Chem. Commun. (2009), 1861-1863; (b) T. Kaczorowski, I. Justyniak, T. Lipińska, J. Lipkowski, and J. Lewiński, J. Am. Chem. Soc. 131 (2009) 5393-5395; (c) V. G. Organo, V. Sgarlata, F. Firouzbakht, and D. M. Rudkevich, Chem. Eur. J. 13 (2007) 4014-4023; (d) T. Iwanaga, R. Nakamoto, M. Yasutake, H.
Takemura, K. Sako, and T. Shinmyozu, Angew. Chem. Int. Ed. 45 (2006) 3643-3647; (e) G. R. Desiraju, Nature 412 (2001) 397.

13. (a) J. Tian, P. K. Thallapally, S. J. Dalgarno, P. B. McGrail, and J. L. Atwood, Angew. Chem. Int. Ed. 47 (2009) 5492-5495; (b) G. Yuan, C. Zhu, W. Xuan, and Y. Cui, Chem. Eur. J. 15 (2009) 6428-6434; (c) A. Comotti, S. Bracco, G. Distefano, and P. Sozzani, Chem. Commun. (2009) 284-286; (d) T. D. Nixon, L. D. Dingwall, J. M. Lynam, and A. C. Whitwood, Chem. Commun. (2009) 2890-2892; (e) P. Dechambenoit, S. Ferlay, N. Kyritsakas, and M. W. Hosseini, J. Am. Chem. Soc. 130 (2008) 17106-17113; (f) N. W. Ockwig, O. Delgado-Friedrichs, M. O'Keefe, and O. M. Yaghi, Acc. Chem. Res. 38 (2005) 176-182; (g) G. Férey, Acc. Chem. Res. 38 (2005) 217-225; (h) C. H. Görbitz, Chem. Eur. J. 13 (2007) 1022-1031.

14. For an overview, see: (a) M. Albrecht and G. van Koten, Angew. Chem. Int. Ed. 40 (2001) 3750-3781; (b) M. E. van der Boom and D. Milstein, Chem. Rev. 103 (2003) 1759-1792; (c) J. T Singleton, Tetrahedron 59 (2003) 1837-1857; (d) D. MoralesMorales and C. M., Jensen, Eds. The Chemistry of Pincer Compounds; Elsevier, Amsterdam, 2007.

15. (a) R. Johansson, L. Öhrström, and O. F. Wendt, Cryst. Growth Des. 7 (2007) 1974-1979; (b) B. F. M.Kimmich, W. J. Marshall, P. J. Fagan, E. Hauptman, and R. M. Bullock, Inorg. Chim. Acta 330 (2002) 52-58; (c) M. T. Johnson, R. Johansson, M. V. Kondrashov, G. Steyl, M. S. G. Ahlquist, A. Roodt, and O. F. Wendt, Organometallics 29 (2010) 3521-3529; (d) R. Johansson, M. Jarenmark, and O. F. Wendt, Organometallics 24 (2005) 4500-4502; (e) M. C. Denney, N. A. Smythe, K. L. Cetto, R. A. Kemp, and K. I. Goldberg, J. Am. Chem. Soc. 128 (2006) 2508-2509; (f) R. Johansson and O. F. Wendt, Organometallics 26 (2007) 2426-2430; (g) M. T. Johnson, M. Cetina, K. Rissanen, and O. F. Wendt, Acta Crystallogr. E66 (2010) m675; (h) G. R. Fulmer, R. P. Muller, R. A. Kemp, and K. I. Goldberg, J. Am. Chem. Soc. 131 (2009) 1346-1347.

16. M. T. Johnson, Z. Džolić, M. Cetina, L. Öhrström, M. Lahtinen, K. Rissanen, and O. F. Wendt, in preparation. 